Original Research Paper

\title{
Nose Color of Charolais $\times$ British Crossbred Beef Steers Alters Body Weight at a Common Degree of Fatness and Marbling Score in Steers Reared Under Similar Management from Birth through Finishing
}

\author{
Zachary K. Smith \\ Department of Animal Science, South Dakota State University, Brookings, SD, USA
}

\author{
Article history \\ Received: 21-07-2020 \\ Revised: 06-10-2020 \\ Accepted: 07-10-2020 \\ E.mail: zachary.smith@sdstate.edu
}

\section{Introduction}

There is inherent variation in the feeder cattle population in the United States. These differences are related to cattle mature size, growth performance, health outcomes and carcass quality and yield grade (Gentry et al., 2020; Smith et al., 2020). These differences can create issues in relation to management of fed cattle populations and harvesting at the appropriate time in order to not receive discounts for cattle that do not meet specific grid specifications for weight, quality and cutability. It is common for feedlots to sort calves based upon frame size, however, depending upon age, frame size might be confounded by body weight. The purpose of this experiment was to determine if nose color of Charolais $\times$ British crossbred beef steers could

\begin{abstract}
This study evaluated differences in nose color (Black or Pink) on carcass traits and mature body weight in Charolais $\times$ British crossbred beef steers. Steers $(\mathrm{n}=180 ; 280 \pm 18.2 \mathrm{~kg})$ were weaned and fed for 244 days until harvest. The hypothesis was that steers with black noses had Black Angus dams and that steers with pink noses had Red Angus dams and that these genotypic differences might influence carcass traits and body weight a common fatness endpoint. Data were analyzed as a randomized complete Cary, NC) with the main effect of nose color and finishing phase pen included as a random effect. Individual steer served as the experimental unit for all analyses. Weaning Body Weight $(\mathrm{BW})$ differed $(P=0.05)$ between black and pink. Final shrunk BW, hot carcass weight, dressing percentage, longissimus muscle area and mRatio did not differ $(P \geq 0.16)$ between black nose or pink. Rib fat depth was greater $(P=0.01)$ for black compared to pink. Measures for kidney-pelvic-heart fat tended to increase $(P=0.07)$ in black nosed steers. Marbling score was greater $(P=0.01)$ in black versus pink nosed steers. Steers with black noses had greater $(P=$ $0.01)$ numerical yield grade and lower $(P=0.01)$ retail yield. Black nosed $(P=0.07)$ to have decreased BW at $28 \%$ EBF. The fistribution of tended Quality Grades tended $(P=0.10)$ to differ between nose classification. Total live weight gain was compromised in the black nosed steers if the steers would have been harvested at an equal fatness endpoint.
\end{abstract}

Keywords: Beef, Crossbred, Feedlot, Marbling, Mature Size be used as a proxy to sort cattle into like outcome groups based upon difference in mature size and carcass quality, both of which are traits that are difficult to determine at the time of placement on feed. The hypothesis was that steers with black noses had Black Angus dams and that steers with pink noses had Red Angus or Crossbred dams and that these genotypic differences in cow biotype would influence carcass traits and body weight a common fatness endpoint.

\section{Materials and Methods}

All procedures related to cattle handling and care were done according to the Guide for the Care and Use of Agricultural Animals in Agricultural Research and Teaching described by (FASS, 1999). 


\section{Phenotypic Data used in the Present Study}

Weaning weight, final Body Weight (BW) and carcass traits were available for a group of steers from a single ranch in Western South Dakota that were managed under similar practices from weaning to harvest at approximately 14 months of age. The steers used in the present analysis were sourced from a ranch in western South Dakota that used Charolais bulls mated to Black British influenced and Red British influenced females. The ranch targets a calving window of approximately $60 \mathrm{~d}$ and all cattle are managed similarly until weaning, it was assumed that all steers used in the present study were of similar age.

\section{Cattle Management from Weaning to Harvest}

Steers $(n=180)$ were weaned at approximately 6 months of age on October 23, 2019 and shipped 513-km to the Ruminant Nutrition Center (RNC) in Brookings, $\mathrm{SD}$, where they were group housed in concrete surface pens for 244 days until harvest on June 22, 2020. Since cattle were group housed, no intake data is available for this retrospective analysis. Upon arrival to the RNC, steers were identified via a unique identification ear tag and vaccinated for: Infectious bovine rhinotracheitis, bovine viral diarrhea 1 and 2, parainfluenza 3 and bovine respiratory syncytial virus (Bovi-Shield Gold 5, Zoetis, Parsippany, NJ) and clostridials (Ultrabac 7/Somubac, Zoetis). The following day steers were administered pouron moxidectin (Cydectin, Bayer, Shawnee Mission, KS). At 14 d post-arrival to the RNC (230 days before harvest) steers were administered a steroidal implant containing 200 $\mathrm{mg}$ of progesterone and $20 \mathrm{mg}$ of estradiol benzoate (Synovex-S, Zoetis) and 132 days before harvest all steers received a terminal implant containing $200 \mathrm{mg}$ of trenbolone acetate and $28 \mathrm{mg}$ of estradiol benzoate (Synovex-PLUS, Zoetis).

\section{Carcass Trait Collection and Calculations}

Steers were used in growing and finishing phase experiments conducted at the RNC prior to harvest. Cattle were shipped on a single day when they were visually appraised to have $1.27 \mathrm{~cm}$ of Rib Fat (RF). Steers were harvested at Tyson Fresh Meats in Dakota City, NE. Hot Carcass Weight (HCW) was recorded during the harvest process and video image data was obtained from the packing plant records for Longissimus Muscle (LM) area, $12^{\text {th }}$ rib fat thickness (RF), Kidney-Pelvic-Heart fat (KPH) and USDA marbling scores. Carcass traits were used to determine USDA Yield Grade according to the USDA regression equation (USDA, 1997). Dressing Percentage (DP) was calculated as $\mathrm{HCW} /($ final $\mathrm{BW} \times 0.96)$. Carcass measurements were used to calculate Empty Body Fat percentage (EBF) according to (Guiroy et al., 2002), Adjusted Final BW at $28 \%$ EBF (AFBW) according to
(Guiroy et al., 2002) and proportion of closely trimmed boneless retail cuts from carcass round, loin, rib and chuck (Retail Yield, RY) according to (Murphey et al., 1960). The mRatio is based upon the Z-Score of traits of interest and was calculated according to the following equation:

$$
\begin{aligned}
& {\left[\frac{(\text { Observed variable } 1-\text { variable } 1 \text { mean })}{\text { variable } 1 \text { standard deviation }}\right]} \\
& -\left[\frac{(\text { Observed variable } 2-\text { variable } 2 \text { mean })}{\text { variable } 2 \text { standard deviation }}\right] .
\end{aligned}
$$

Means and standard deviations used were from the whole population ( $\mathrm{n}=180$ steers). When both variables deviate normally, the resulting value is zero. The mRatio reported here used marbling and RF depth as variables 1 and 2 , respectively.

\section{Statistical Analysis}

Descriptive statistics of the entire population were determined using Proc Univariate in SAS 9.4 (SAS Inst. Inc., Cary, NC). Analysis of variance for all continuous variables were conducted using the GLIMMIX procedure of SAS 9.4 (SAS Inst. Inc.). Chi square analysis for the distribution of USDA Yield and Quality grades was performed using the FREQ procedure in SAS 9.4 (SAS Inst. Inc.). Individual steer served as the experimental unit for all analyses. The model included the fixed effect of nose color (black or pink) and finishing phase experiment pen was considered a random variable. Due to unequal observations in each group, the Kenward-Roger degree of freedom adjustment was used for data continuous in nature. Differences were evaluated by the Pairwise Differences and lines (PDIFF LINES) statement of SAS 9.4 (SAS Inst. Inc.). An $\alpha$ of 0.05 determined significance and an $\alpha$ of 0.06 to 0.10 was considered a tendency.

\section{Results}

Descriptive statistics of the overall population of Charolais $\times$ British crossbred steers is located in Table 1 .

Body weight and carcass trait responses can be found in Table 2. Weaning Body Weight (BW) differed $(P=$ 0.05 ) by $2.1 \%$ between black and pink nose steers. Final shrunk BW, HCW, DP, LM area and mRatio was not different $(P \geq 0.16)$ between black nosed or pink nosed steers. Rib fat depth was $11.9 \%$ greater $(P=0.01)$ for black nosed steers compared to pink nosed steers. Measures for kidney-pelvic-heart fat tended to increase by $2.2 \%(P=0.07)$ in black nosed steers compared to pink nosed steers. Marbling score was $7.0 \%$ greater $(P=$ 0.01) in black nosed steers compared to pink nosed steers. Steers with black noses had greater $(P=0.01)$ numerical yield grade $(8.8 \%)$ and lower $(P=0.01)$ retail yield $(1.0 \%)$ compared to steers with pink noses. Black 
nosed steers had greater $(P=0.01)$ estimated EBF by $3.8 \%$ compared to pink nosed steers and tended $(P=$ 0.07 ) to have decreased $\mathrm{BW}$ at $28 \% \mathrm{EBF}$ by $2.1 \%$ compared to pink nosed steers. Distribution of USDA Yield Grades did not differ $(P=0.16)$ between black and pink nosed steers. The distribution of USDA Quality Grades tended $(P=0.10)$ to differ between nose classification with fewer USDA Select graded carcasses and greater USDA High Choice graded carcasses in black nosed steers compared to pink nosed steers.

Table 1: Descriptive statistics for Body Weight (BW) and carcass traits of Charolais $\times$ British crossbred steers $(n=180)$

\begin{tabular}{|c|c|c|}
\hline Item & Mean & Standard deviation \\
\hline Weaning BW, kg & 280 & 18.2 \\
\hline Final shrunk (4\%) BW, kg & 657 & 42.5 \\
\hline $\mathrm{HCW}, \mathrm{kg}$ & 424 & 29.3 \\
\hline $\mathrm{DP}, \% 1$ & 64.57 & 1.973 \\
\hline Longissimus muscle area, $\mathrm{cm}^{2}$ & 98.90 & 7.090 \\
\hline Rib fat, $\mathrm{cm}$ & 1.31 & 0.326 \\
\hline Kidney-pelvic-heart fat, \% & 1.78 & 0.142 \\
\hline Marbling score ${ }^{2}$ & 494 & 77.9 \\
\hline Calculated Yield Grade ${ }^{3}$ & 2.90 & 0.572 \\
\hline Retail Yield, $\%^{4}$ & 50.98 & 1.176 \\
\hline Estimated Empty Body Fat (EBF), $\%^{5}$ & 30.32 & 2.151 \\
\hline BW at $28 \% \mathrm{EBF}, \mathrm{kg}^{5}$ & 625 & 42.7 \\
\hline
\end{tabular}

${ }^{1}$ Calculated as: $\mathrm{HCW} /$ final BW pencil shrunk $4 \%$

${ }^{2} 400=\operatorname{small}^{00}$ (USDA Low Choice)

${ }^{3}$ Calculated according to the USDA regression Equation (USDA, 1997)

${ }^{4}$ Closely trimmed retail cuts from the round, loin, rib and chuck according to (Murphey et al., 1960)

${ }^{5}$ Calculated according to (Guiroy et al., 2002)

Table 2: Least squares means for Body Weight (BW) and carcass traits of Charolais crossbred steers with black or pink noses.

\begin{tabular}{|c|c|c|c|c|}
\hline & \multicolumn{2}{|c|}{ Nose color } & \multirow[b]{2}{*}{ SEM } & \multirow[b]{2}{*}{$P$ - value } \\
\hline & Black & Pink & & \\
\hline Steers, $\mathrm{n}$ & 46 & 134 & - & - \\
\hline Weaning BW, kg & 285 & 279 & 3.0 & 0.05 \\
\hline Final shrunk (4\%) BW, kg & 665 & 654 & 7.2 & 0.16 \\
\hline $\mathrm{HCW}, \mathrm{kg}$ & 427 & 423 & 5.0 & 0.46 \\
\hline $\mathrm{DP}, \%^{1}$ & 64.21 & 64.68 & 0.332 & 0.40 \\
\hline Longissimus muscle area, $\mathrm{cm}^{2}$ & 98.20 & 99.10 & 1.210 & 0.47 \\
\hline Rib fat, cm & 1.43 & 1.27 & 0.050 & 0.01 \\
\hline Kidney-pelvic-heart fat, \% & 1.81 & 1.77 & 0.024 & 0.07 \\
\hline Marbling score $^{2}$ & 520 & 485 & 13.1 & 0.01 \\
\hline Calculated Yield Grade ${ }^{3}$ & 3.09 & 2.83 & 0.096 & 0.01 \\
\hline Retail Yield, $\%{ }^{4}$ & 50.59 & 51.11 & 0.198 & 0.01 \\
\hline Estimated Empty Body Fat (EBF), $\%^{5}$ & 31.19 & 30.03 & 0.358 & 0.01 \\
\hline $\mathrm{BW}$ at $28 \% \mathrm{EBF}, \mathrm{kg}^{5}$ & 616 & 629 & 7.3 & 0.07 \\
\hline mRatio & -0.023 & 0.024 & 0.1988 & 0.81 \\
\hline \multicolumn{5}{|l|}{ USDA Yield Distribution, \% } \\
\hline 1 & 0.0 & 4.4 & - & 0.16 \\
\hline 2 & 45.6 & 57.8 & - & - \\
\hline 3 & 50.0 & 34.8 & - & - \\
\hline 4 & 4.4 & 3.0 & - & - \\
\hline 5 & 0.0 & 0.0 & - & - \\
\hline \multicolumn{5}{|l|}{ USDA Quality Grade Distribution, $\%$} \\
\hline Select & 4.4 & 12.4 & - & 0.10 \\
\hline Low Choice & 43.4 & 50.1 & - & - \\
\hline Average Choice & 34.8 & 30.3 & - & - \\
\hline High Choice & 15.2 & 7.2 & - & - \\
\hline Prime & 2.2 & 0.0 & - & - \\
\hline
\end{tabular}

${ }^{1}$ Calculated as: HCW/final BW pencil shrunk $4 \%$

${ }^{2} 400=$ small $^{00}$ (USDA Low Choice)

${ }^{3}$ Calculated according to the USDA regression Equation (USDA, 1997)

${ }^{4}$ Closely trimmed retail cuts from the round, loin, rib and chuck according to (Murphey et al., 1960)

${ }^{5}$ Calculated according to (Guiroy et al., 2002) 


\section{Discussion}

Rapid increases in finishing input costs reduce profit margins for cattle finishing operations. There are distinct differences in the United States Feeder cattle population and these inherent differences must be managed by the cattle feeder in order to produce an acceptable uniform product that is desired by consumers (Smith et al., 2020). Cattle marketed in like groups are at a lesser risk to receive severe discounts at the packing plant. Additionally, specific breeds or combination of breeds are crucial to cow-calf operator profitability (McCabe et al., 2019) depending upon the geographical region in which the operation is located. It has been demonstrated that Red-Angus sired calves garner a premium at weaning compared to Black-Angus sired calves and that Charolais sired calves are intermediate (McCabe et al., 2019). It is perceived that black colored cattle have a greater propensity to marble and will garner a premium at harvest (McCabe et al., 2019), however, this is not demonstrated when purchase price of calves are evaluated. Few studies have illustrated the economic value of differing breeds and phenotypes of feeder cattle (Halfman et al., 2009; McCabe et al., 2019) and to our knowledge no studies have investigated differing genotypes and phenotypes of steers calves maintained under similar management from birth, through weaning, backgrounding and finishing and subsequently through the harvest process.

Gentry et al. (2020) indicated that some producers might use visual appraisal to recognize differences in frame size and subsequently observe difference in marbling and conclude that marbling is inversely related to frame size. Weaning weight was greater in black nosed steers compared to pink nosed steers. Gentry et al. (2020) indicated that weaning weight could be used as a proxy for frame size determination if calves were managed under similar conditions and of similar age at the time of weaning. Steers used in the present analysis were from a calving season that was approximately 60-d in length, thus it is assumed that the steers calves used in the present analysis were of similar age.

Greater weaning weight did not result in greater final shrunk BW and resulted in decreased mature BW (BW at $28 \%$ EBF) in the present study. This finding is in contrast to what has been demonstrated previously (Gentry et al., 2020). Hot carcass weight was similar between nose classification, but RF and USDA marbling scores differed. Steers from the black nose classification were fatter at harvest as indicated by greater RF depth and greater estimated EBF and this is to be expected when the values used to calculated this variable differed and the fact that RF carries the highest input in the regression equation used to determine EBF (Guiroy et al., 2001; 2002; Smith et al., 2018; 2019; Gentry et al., 2020). To answer the question of whether increased marbling scores observed for the black nosed steers was an artifact of progression in the growth curve or due to increased RF, this finding was further investigated using the mRatio. Use of the mRatio is an unbiased approach to looking for whether differences in marbling were due to progression of growth or due to increased RF. No difference in the mRatio between nose classifications suggests that the increased marbling scores were indeed due to the progression in the growth curve. Assuming the black and pink nosed steers were of a common age, the similar HCW and difference in RF depth indicate that the black nosed steers were of smaller framed size genetics. This, however, does not rule out that the marbling Expected Progeny Differences may be confounded in the parents of these steers. The observed difference in RF was not dramatic. It would be valuable to be able to calculate how much frame size is represented by 0.16 $\mathrm{cm}$ of RF. Other potentially confounding factors could be genomics for dry matter intake, which was not available in the present experiment due to steers being group housed from weaning to harvest.

\section{Conclusion}

Total live weight gain was compromised in the black nosed steers if all steers would have been harvested at an equal chemical maturity. Greater potential live weight gain and lighter weights at the time of purchase indicate that pink nosed steers could potentially be worth more $(\$ / 45.4-\mathrm{kg})$ as feeders than their black nosed counterparts. More of this type of research should be conducted in order to ascertain real value discounts that should be applied to feeder cattle populations or varying genotype and phenotype.

\section{Acknowledgment}

The author wishes to acknowledge the staff of the South Dakota State University Ruminant Nutrition Center for the daily care and management for the cattle used in present study.

\section{Funding}

National Institute of Food and Agriculture, the South Dakota State University Experiment Station (HATCHSD00H690-19) and the Beef Nutrition Program at South Dakota State University.

\section{Ethical Approval}

All data used in the present study was obtained from previously conducted feeding experiments (Approval Numbers: 19-054E and 1912-066E). Therefore, it was not necessary to obtain animal care and use committee approval in advance of conducting the present analysis. 


\section{Disclosure Statement}

No potential conflict of interest is reported by the author.

\section{References}

FASS. (1999). Guide for the care and use of agricultural animals in agricultural research and teaching. Federation of Animal Science Societies.

Gentry, W. W., Blom, E. J., Pritchard, R. H., \& Hales, K. E. (2020). Effect of anabolic hormone exposure during the backgrounding-phase in calf-fed steers of different mature sizes. Translational Animal Science, 4(2), txaa076.

Guiroy, P. J., Fox, D. G., Tedeschi, L. O., Baker, M. J., \& Cravey, M. D. (2001). Predicting individual feed requirements of cattle fed in groups. Journal of animal science, 79(8), 1983-1995.

Guiroy, P. J., Tedeschi, L. O., Fox, D. G., \& Hutcheson, J. P. (2002). The effects of implant strategy on finished body weight of beef cattle. Journal of Animal Science, 80(7), 1791-1800.

Halfman, B., Lehmkuhler, J. W., \& Cox, T. (2009). Factors affecting Wisconsin feeder calf prices at a local livestock market. Journal of Extension, 47(6), 1-8.

McCabe, E. D., King, M. E., Fike, K. E., Hill, K. L., Rogers, G. M., \& Odde, K. G. (2019). Breed composition affects the sale price of beef steer and heifer calves sold through video auctions from 2010 through 2016. Applied Animal Science, 35(2), 221-226.
Murphey, C. E., Hallett, D. K., Tyler, W. E., \& Pierce Jr, J. C. (1960). Estimating yields of retail cuts from beef carcasses. J. Anim. Sci, 19(Suppl 1), 1240.

Smith, Z. K., Anderson, P. T., \& Johnson, B. J. (2020). Finishing Cattle in All-Natural and Conventional Production Systems. Open Journal of Animal Sciences, 10(02), 237.

Smith, Z. K., Holland, B. P., Word, A. B., Crawford, G. I., Nichols, W. N., Nuttelman, B. L., ... \& Johnson, B. J. (2019). Effects of a single initial and delayed release implant on arrival compared with a noncoated initial implant and a non-coated terminal implant in heifers fed across various days on feed. Translational Animal Science, 3(4), 1182-1193.

Smith, Z. K., Thompson, A. J., Hutcheson, J. P., Nichols, W. T., \& Johnson, B. J. (2018). Evaluation of coated steroidal implants containing trenbolone acetate and estradiol-17 $\beta$ on live performance, carcass traits and sera metabolites in finishing steers. Journal of animal science, 96(5), 1704-1723.

USDA, (1997). United States standards for grades of beef carcasses. 